\title{
UMBATRA
}

Indonesian Journal of Anthropology

Volume 4 (2) Desember 2019 || eISSN 2528-1569

pISSN 2528-2115 || http://jurnal.unpad.ac.id/umbara

DOI : 10.24198/umbara.v4i2.20461

\section{Gender dan Mekanisasi: Pengalaman Pekerja Perempuan Berpartisipasi dalam Kelompok Petik Mesin di Perkebunan Teh Gambung, Jawa Barat}

\author{
Kralawi Sita \\ Pusat Penelitian Teh dan Kina \\ kralawi.sita@gmail.com
}

\begin{abstract}
Mechanization in the tea harvesting process commonly leads to gender imbalance, as male workers receive more benefit than female. However, this phenomenon does not the case in Gambung Tea Plantation. Female participation in the machine harvesting is high as they become the operator of tea plucking machines. This phenomenon is worth to study in particular to explore female workers' personal experience in mechanical tea plucking. This research applies descriptive qualitative method with phenomenology approach. Female and male machine picker becomes the main subject in this study. Primary data were collected through observation, documentation, interviews and Focused Group Discussion with female and male tea plucker. Triangulation techniques were applied to ensure data validity. This study suggests that the mechanization process in Gambung Tea Plantation has created a new gender division of labour where male and female work together in a team to operate the machine. Female workers show quality of work better than male worker. Amidst the efforts of female workers to participate in the mechanization there are risks and constraints for them, such as less-gender friendly equipment, lack of access and control to resources, cultural norms, values in the society.
\end{abstract}

Keywords: gender, mechanization, participation, tea plucker, tea plucking machine

\begin{abstract}
Abstrak
Mekanisasi di perkebunan teh berupa penggunaan mesin petik teh untuk panen secara umum berdampak pada ketimpangan gender. Hal ini karena penerima manfaat mekanisasi lebih banyak laki-laki daripada perempuan. Namun, di Perkebunan Gambung hal ini tidak terjadi. Partisipasi perempuan di perkebunan ini cukup signifikan sebagai operator mesin petik teh. Ketiadaan dampak negatif intervensi mekanisasi di Perkebunan teh Gambung sangat menarik untuk diteliti, terutama eksplorasi mengenai pengalaman perempuan dalam pemetikan teh mekanis. Penelitian ini menggunakan metode kualitatif deskriptif dengan pendekatan fenomenologi. Subjek penelitian ini adalah laki-laki dan perempuan pemetik mesin. Pengambilan data dilakukan melalui pengamatan, dokumentasi, wawancara dan focused group discussion. Validitas data dijamin dengan teknik triangulasi. Hasil penelitian menunjukkan
\end{abstract}


bahwa proses mekanisasi di perkebunan teh Gambung telah menciptakan pola tenaga kerja (realokasi) gender baru yang terwujud dalam sebuah kelembagaan baru berupa kelompok petik mesin. Partisipasi perempuan terlihat nyata, kualitas kerja mereka pun lebih baik daripada laki-laki, dan pembagian kerja yang seimbang. Namun di tengah usaha keras perempuan untuk turut merasakan manfaat teknologi mekanisasi tersebut ada banyak resiko dan kendala yang membatasi adopsi perempuan terhadap teknologi, diantaranya teknologi yang belum ramah gender, kurangnya akses dan kontrol perempuan terhadap sumber daya, dan norma budaya, nilai di masyarakat.

Kata kunci : gender, mekanisasi, partisipasi, pemetik teh, mesin petik teh

\section{Pendahuluan}

Perkebunan teh identik dengan pekerja perempuan dengan keterampilan "nimble fingers" mereka memetik pucuk-pucuk daun teh (Hubeis, 2010). Perempuan pemetik teh adalah figur penting dalam rantai produksi teh di Indonesia. Figur mereka bahkan dimunculkan pada uang pecahan Rp 20.000 sebagai bentuk penghargaan atas peran mereka dalam produksi hasil perkebunan terbesar di Indonesia.

Dewasa ini, seiring dengan adanya intervensi mekanisasi, perkebunan teh mulai menggunakan mesin petik yang menggantikan peran tangan-tangan terampil pemetik teh perempuan, dengan alasan efisiensi (Maina dan Kaluli, n.d.; Ongong dan Ochieng, 2013), peningkatan produktivitas (Dalimoenthe dan Kartawijaya, 2000; Kusumawati, 2013), dan kelangkaan tenaga kerja pertanian (Dalimoenthe dan Kartawijaya, 2000; Agus, 2016; Lei, 2017; Kusumawati, 2013). Penggunaan mesin petik teh membuka peluang ketimpangan gender dalam konteks sosial ekonomi, yaitu saat perempuan kehilangan kesempatan berpartisipasi dalam dunia kerja. Studi sebelumnya dalam konteks mekanisasi terutama penggunaan mesin petik pada proses pemetikan teh, masih menemukan adanya dominasi pekerja laki-laki. Pekerja perempuan tidak terlibat dalam pemetikan dengan mesin. Mereka hanya menggunakan tangan dan gunting petik dengan alasan alat mesin petik cukup berat untuk dioperasikan oleh perempuan dan mesin pun belum ergonomis bagi tubuh perempuan (Sita dan Herawati, 2017).

Penerima manfaat mekanisasi memang lebih banyak laki-laki, namun minat perempuan untuk mencoba dan ikut menggunakan mesin petik cukup kuat. Hal itu menunjukkan upaya mereka mempertahankan peran dan eksistensi diri dalam rantai produksi teh dan tujuan untuk memperbaiki keadaan sosial ekonomi rumah tangga mereka. Fenomena ini tampak pada para pekerja perempuan pemetik teh di Perkebunan Gambung.

Beberapa studi sebelumnya mengenai mekanisasi, menunjukkan adanya harapan pemberdayaan gender sebagai proses dan dampak dari intervensi mekanisasi pertanian secara luas (Elias, 2015; Tsusaka, et al., 2016); Kawarazuka et al., 2018). Studi-studi tersebut menjadi rujukan penting bagi studi mengenai dampak intervensi mekanisasi pemetikan teh yang terjadi di Perkebunan Gambung pada pekerja perempuan. Di perkebunan ini, perempuan pemetik teh ikut terlibat di dalam mekanisasi pemetikan teh. Penelitian ini mendeskripsikan pengalaman pekerja petik perempuan dalam partisipasi mereka di kelompok petik mesin.

\section{Kajian Pustaka}


FAO (Food and Agriculture Organization) mendefinisikan istilah "mekanisasi pertanian" sebagai pembuatan, distribusi, dan pengoperasian alat, peralatan, mesin dan peralatan bertenaga sebagai input untuk pengembangan lahan pertanian dan produksi pertanian serta untuk panen dan pemrosesan hasil utama pertanian (Sims dan Kienzle, 2017). Secara umum, tiga sumber daya yang digunakan di pertanian adalah: manual, hewan, dan motor (dengan bahan bakar fosil dan listrik). Di dalam kaitannya dengan gender, mekanisasi pertanian sering kali mendorong negosiasi ulang tentang tenaga kerja. Ketika tenaga manusia dapat digantikan oleh mesin, seringkali laki-laki yang mendapatkan kesempatan lebih untuk terlibat di dalam pekerjaan menggunakan mesin, dibnding tenaga kerja perempuan (World Bank, 2008; van Eerdewijk dan Danielsen, 2015).

Feminisme pertanian menawarkan serangkaian peningkatan peluang mekanisasi pertanian di tingkat pertanian dan dalam rantai nilai pangan pertanian yang berkelanjutan secara ekonomi, lingkungan, dan sosial. Perempuan telah terbukti banyak berperan dan cenderung mahir dalam pengelolaan sumber daya alam. Oleh karena itu, dalam pengembangan mekanisasi pertanian penting untuk menggabungkan pengetahuan perempuan dengan penggunaan mesin yang sesuai dan dirancang untuk digunakan oleh perempuan agar produksi pangan menjadi lebih berkelanjutan secara lingkungan (Sims, Hilmi, dan Kienzle, 2016).

Keith Davis dalam Tangkilisan (2005) mendefinisikan partisipasi sebagai "an individual as mental and emotional involment in a group situation that encourages him to contribute to group goals and to share responsibility for them", artinya keterlibatan pikiran dan emosi seseorang dalam situasi kelompok yang memberikan semangat untuk menyokong tujuan-tujuan kelompok dan mengambil bagian tanggung jawab untuk kelompok itu sendiri.
Kunci pemikiran dari definisi partisipasi tersebut adalah keterlibatan mental dan emosi. Selanjutnya Davis juga menyebutkan bahwa terdapat 3 (tiga) unsur pokok dalam partisipasi, yaitu 1) keterlibatan mental dan emosi individu dalam melakukan aktivitas kelompok; 2) motivasi individu untuk berinisiatif memberikan kontribusi yang dapat berwujud barang, jasa, ide, tenaga dan keterampilan; dan 3) timbulnya rasa tanggung jawab dalam diri individu terhadap aktivitas kelompok dalam usaha pencapaian tujuan. Dengan demikian, partisipasi dapat diartikan sebagai sebuah keterlibatan atau keikutsertaan seseorang dalam suatu kegiatan kelompok yang meliputi mental, emosi, motivasi dan rasa tanggung jawab terhadap pencapaian tujuan kelompoknya.

Partisipasi perempuan menjadi satu dari lima dimensi utama dalam konsep pemberdayaan perempuan (Sukesi, 1999) yang bertujuan mengorganisir perempuan agar dapat berperan dalam proses pengambilan keputusan bagi kepentingan mereka sendiri. Menurut Verick (2018), partisipasi tenaga kerja perempuan menjadi pendorong dan manfaat yang penting bagi pertumbuhan dan pembangunan. Semakin banyak perempuan memasuki dalam angkatan kerja, maka perekonomian memiliki potensi untuk tumbuh lebih cepat. Hal ini selanjutnya dapat meningkatkan pendapatan rumah tangga dan membantu keluarga untuk keluar dari kemiskinan; serta meningkatkan kemampuan keluarga dalam mengonsumsi barang dan jasa.

Data The Global Gender Gap Report tahun 2018 dari The World Economic Forum, menunjukkan bahwa kesenjangan gender dalam bidang ekonomi berupa partisipasi dan kesempatan perempuan di sektor ekonomi di Indonesia masih lebar, yaitu berada pada skor 0,629 dalam hal partisipasi, pengupahan, dan kemajuan (World Economic Forum, 2018). Verick (2018) mengungkapkan bahwa khusus untuk di negara-negara berkembang, penting 
untuk memahami partisipasi perempuan dalam kerja, dan jenis pekerjaan yang dapat diakses oleh perempuan yang secara umum cenderung dibayar lebih rendah dan dipekerjakan dalam pekerjaan dengan produktivitas rendah. Hal ini penting karena partisipasi perempuan merupakan pendorong pertumbuhan suatu negara dan dapat menjadi mekanisme penanggulangan dalam menanggapi guncangan ekonomi yang melanda rumah tangga.

Puspitawati (2013) mengungkapkan konsep gender yang dimotori oleh budaya patriarki menafsirkan perbedaan biologis sebagai indikator kepantasan dalam berperilaku antara laki-laki dan perempuan yang akhirnya berujung pada pembatasan hak, akses, partisipasi, kontrol perempuan dalam menikmati manfaat dari sumber daya dan informasi (Puspitawati, 2013). Akibat dari konsep ini, tuntutan peran, tugas, kedudukan dan kewajiban yang pantas dilakukan oleh laki-laki atau perempuan dan yang tidak pantas dilakukan oleh laki-laki atau perempuan sangat bervariasi dari masyarakat satu ke masyarakat lainnya. Ada sebagian masyarakat yang sangat kaku membatasi peran yang pantas dilakukan baik oleh laki-laki maupun perempuan, ada juga sebagian masyarakat yang fleksibel dalam memperbolehkan laki-laki dan perempuan melakukan aktivitas sehari-hari.

Tiga teori utama mengenai kesetaraan dan keadilan gender menurut Edward Wilson dalam Sasongko (2009), yaitu teori nurture (konstruksi budaya), teori nature (alamiah), dan teori equilibrium (keseimbangan). Teori nurture menjelaskan bahwa perbedaan peran dan tugas perempuan dan laki-laki pada hakikatnya adalah hasil konstruksi sosial budaya. Teori nature menjelaskan bahwa perbedaan peran dan tugas perempuan dan laki-laki adalah kodrat sehingga tidak dapat diubah dan bersifat universal. Teori equilibrium menjelaskan bahwa peran dan tugas perempuan dan laki-laki dapat dilakukan secara kompromistis, saling bekerja sama dengan menekankan pada konsep kemitraan dan keharmonisan dalam hubungan antara perempuan dan laki-laki.

Nugroho (2008) menyebutkan bahwa kesetaraan dan keadilan gender ditandai dengan tidak adanya diskriminasi antara perempuan dan laki-laki sehingga perempuan dan laki-laki memiliki akses, kesempatan berpartisipasi, dan kontrol atas pembangunan serta memperoleh manfaat yang setara dan adil dari pembangunan. Sasongko (2009) menyebutkan kesetaraan gender adalah kesamaan kondisi bagi laki-laki dan perempuan untuk memperoleh hak-haknya sebagai manusia, agar mampu berperan dan berpartisipasi dalam kegiatan politik, ekonomi, sosial budaya, pertahanan dan keamanan dan kesamaan dalam menikmati hasil pembangunan.

\section{Metode}

Penelitian ini menggunakan metode kualitatif deskriptif dengan pendekatan fenomenologi. Perkebunan Gambung, Jawa Barat dipilih sebagai lokasi studi kasus karena perkebunan ini sebagai salah satu pionir dalam penerapan teknologi mekanisasi pemetikan teh di Indonesia. Perkebunan ini menjadi bagian dari kebun percobaan milik Pusat Penelitian Teh dan Kina Jawa Barat. Subjek penelitian ini adalah pemetik mesin perempuan dan laki-laki atau biasa disebut operator mesin petik. Mereka yang tergabung dalam kelompok mesin petik teh yang terdiri atas laki-laki dan perempuan. Subyek penelitian dipilih secara purposif berdasarkan kesediaan mereka untuk mengeksplorasi dan mengartikulasikan pengalaman mereka secara sadar (Cresswel, 2013). Teknik pengumpulan data dilakukan dengan observasi, dokumentasi, wawancara, dan Focus Group Discussion (FGD). Wawancara dilakukan pada 5 (lima) orang, yang terdiri atas 4 (empat) perempuan pelopor petik mesin dan 1 (satu) mandor petik mesin. FGD dilakukan di kantor kebun Gambung, dengan jumlah 
partisipan sebanyak 10 (sepuluh) orang, meliputi manajer, asisten manajer, para mandor, dan karyawan kebun yang terkait.

Data pengalaman partisipasi perempuan pemetik teh di Perkebunan Gambung dianalisis dengan mengikuti prinsip analisa data kualitatif, yaitu melalui tiga tahap, yaitu reduksi data, penyajian data, dan penarikan kesimpulan. Validitas data dijamin dengan menggunakan teknik triangulasi pada berbagai jenis sumber yang berbeda seperti orang, waktu dan ruang sehingga ditemukan data yang konsisten (Huberman dan Miles, 2002).

\section{Hasil dan Pembahasan}

Awal mula mesin petik teh secara serempak dioperasikan di dua Kebun Gambung, yaitu Kebun Gambung Utara dan Gambung Selatan pada tahun 2016. Operator mesin petik semula hanya diperuntukkan untuk laki-laki sedangkan perempuan hanya bertugas mengumpulkan dan menyeleksi pucuk. Hampir seluruh pekerja petik telah memiliki pengalaman sebagai buruh petik teh secara manual dengan tangan dan dengan gunting selama rata-rata lebih dari 15 tahun, tapi tidak banyak diantara mereka berminat untuk beralih menjadi operator pemetik mesin. Risiko yang besar bagi kesehatan menjadi alasan mereka tidak turut serta menjadi operator mesin petik, seperti penuturan Ibu Nana:

"Risiko menjadi operator mesin petik sangat banyak, membawa mesin petik bukan pekerjaan yang mudah dan ringan, mesin petik memiliki getaran yang sangat kuat, biasanya berpengaruh pada badan sepulang kerja jadi sering merasakan pegal-pegal, dan suara bising dari knalpot mesin bikin pendengaran sering sakit, kaki tangan dan pundak menahan beban mesin petik dan risiko jatuh terkilir bila lorong petik licin" (Wawancara dengan Ibu Nana, tanggal 22 Juli 2018).
Namun, beberapa pekerja petik perempuan, karena rasa ingin tahu dan minat yang tinggi serta tekad yang kuat, beberapa perempuan pemetik teh yang semula memetik dengan gunting mulai ingin "coba-coba" menggunakan mesin. Mereka tidak terlalu memikirkan risiko seperti rekan-rekan mereka lainnya. Selain jumlah penghasilan yang lebih banyak dari upah metik secara manual atau gunting, kebanggaan sebagai perempuan yang direkrut sebagai operator menjadi alasan beberapa perempuan pemetik manual beralih menjadi operator mesin. Fenomena ini sejalan dengan teori Lyana (2017) mengenai motif tuntutan ekonomi keluarga dan pencarian eksistensi diri dapat menjadi motif pendorong mengapa semakin banyak wanita memilih untuk bekerja. Alasan ekonomi dan eksistensi diri ini merupakan bagian dari wujud subjektivitas seksual perempuan (Elianna, Dwiningtyas, dan Rahmiaji, 2014) di mana perempuan telah menempatkan diri sebagai subjek secara sadar, memiliki kepercayaan diri, berani mengambil keputusan (risiko), memiliki suatu kebanggaan tersendiri, memiliki eksistensi di ranah privat dan publik, sehingga posisi perempuan sebagai istri dalam rumah tangga keluarga yang dibangun pun setara dengan suaminya. Hal ini diperkuat oleh penyataan salah satu operator mesin:

"Semakin lama orang-orang semakin naik gengsi berprofesi sebagai pemetik, dan tidak diminati, maka dipromosikanlah mesin petik ....... Perekrutan operator dilakukan oleh mandor petik mesin. Kriteria calon operator yang dipilih seperti keseriusan dalam bekerja dan dipandang mampu mengoperasikan mesin petik. Ini menumbuhkan kebanggaan bagi para operator perempuan dan menciptakan posisi baru bagi pemetik perempuan dalam pembagian tenaga kerja petik diluar petik tangan dan petik gunting". (FGD, tanggal 25 Juli 2018). 
Selain rasa kebanggaan, rasa memiliki dan tanggung jawab sebagai operator mesin petik juga perlahan tumbuh dalam diri para operator di kelompok mesin petik. Apabila terjadi kerusakan pada mesin dan komponen yang sifatnya kecil, anggota kelompok berinisiatif segera memperbaiki bahkan membeli spare part alat yang rusak tersebut dengan uang mereka sendiri (lihat Gambar 1). Hal ini dimotivasi oleh kesadaran mereka akan dampak kerusakan mesin pada kinerja dan pendapatan mereka. Fenomena ini selaras dengan temuan Larasati (2017) bahwa perempuan yang telah terbiasa dibebani oleh kerja ganda, akan lebih mudah terbiasa menghadapi masalah-masalah terkait pekerjaannya.

Pembagian kerja dalam perbaikan kerusakan komponen mesin petik masih identik berdasarkan stereotip gender yang melekat antara perempuan dan laki-laki. Stereotip dan stigma perempuan yang identik dengan pekerjaan halus apabila tidak diminimalisir dapat berefek negatif dan melemahkan semangat bekerja perempuan (Larasati, 2017).

"Kalo balon penampung pucuk rusak, selalu kami jahit sendiri. Menunggu kebun untuk memperbaikinya, lama... lagian kalo bolong masih bisa dijahit sendiri. Jarum dan benangnya untuk jahit, kami bawa sendiri dari rumah dan selalu dibawa saat kerja. Yang biasa jahit balonnya yaa... operator perempuannya. Nah, kalo terkait spare part mesin, baru biasanya mandor dan operator laki-laki yang benerinnya. Sama-sama bagi tugas saja...". (Wawancara dengan Ibu Eni, tanggal 22 Juli 2018).

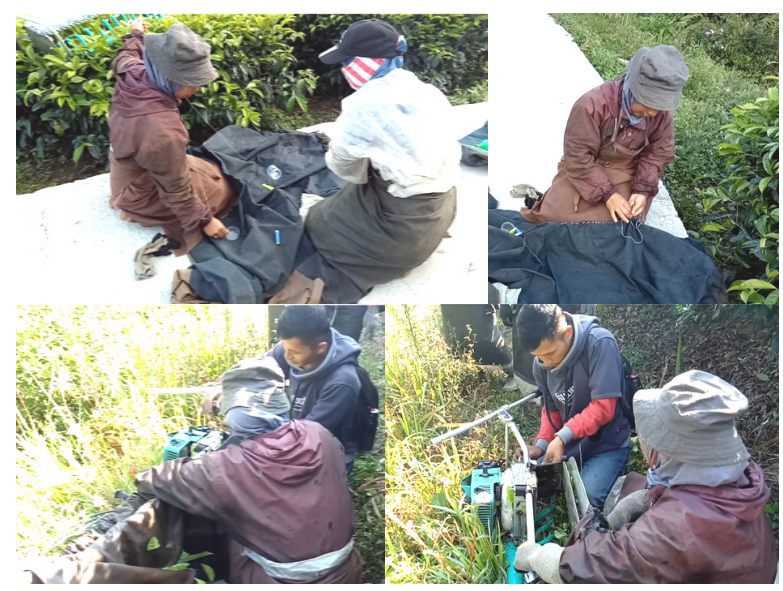

Gambar 1. Kegiatan memperbaiki kerusakan balon penampung pucuk (oleh operator perempuan) dan kerusakan mesin petik (oleh operator laki-laki)

Bentuk inisiatif bersama ini menunjukkan sebuah wujud partisipasi perempuan dalam keberanian pengambilan keputusan atas masalah yang dihadapi kelompoknya dengan berkontribusi dalam ide, materi, tenaga dan keterampilan yang dimiliki untuk membantu memecahkan masalah yang timbul dalam pekerjaan. Karakteristik sistem kerja kelompok petik berbeda dengan kelompok petik manual atau gunting. Sistem kerja kelompok petik mesin bersifat kolektif, yaitu pendapatan akan dibagi rata berdasarkan capaian kinerja bersama dalam satu kelompok. Hal ini berbeda dengan sistem kerja kelompok gunting yang cenderung hasil kerjanya berdasarkan capaian kerja individual. Mereka sangat menyadari bahwa apabila masalah mesin rusak tidak diselesaikan maka akan berpengaruh pada kinerja kelompok. Selain itu, antar anggota kelompok petik mesin baik operator perempuan maupun laki-laki berusaha membangun relasi kerja yang harmonis. Mereka saling melakukan evaluasi dan penguatan satu sama lain atas kualitas pekerjaan dan peran masing-masing di dalam kelompoknya.

Kelembagaan baru berupa kelompok mesin petik dibentuk melalui instruksi mandor di lini bawah. Setiap kelompok mesin petik terdiri atas lima orang anggota, tiga sebagai operator, 
dua lainnya bertugas sebagai pengumpul dan penyeleksi pucuk. Jenis tugas operator berbeda satu sama lain, yaitu terdiri atas driver (supir), co-driver (kondektur), dan pemegang balon penampung pucuk. Di dalam satu kelompok mesin petik terdiri atas anggota perempuan dan laki-laki. Setiap anggota perempuan dan laki-laki, dengan mempertimbangkan kondisi kebun teh pada saat "hanca petikan" (luas areal yang harus selesai dipetik pada satu hari), bekerja secara bergiliran, berganti peran, baik sebagai operator dan non operator. Tidak ada peran yang tetap antar anggota laki-laki dan perempuan, Mereka saling membantu terutama pada saat pengangkutan pucuk dari kebun ke los pucuk. Operator perempuan diberikan cukup keleluasaan untuk berpartisipasi dalam perencanaan dan pelaksanaan pembagian kerja kelompok petik mesin. Ini menunjukkan bahwa kelembagaan baru yang berwujud kelompok petik mesin berpotensi memberikan ruang untuk upaya kesetaraan gender (Sasongko, 2009; Nugroho, 2008) dalam partisipasi tenaga kerja perempuan di perkebunan teh.

Satu-satunya pekerjaan yang selalu dilakukan oleh laki-laki adalah babad lorong petik (Gambar 2.) karena dalam melakukan pekerjaan tersebut membutuhkan "golok" (senjata pisau yang berukuran besar dan panjang) yang biasa dibawa dan digunakan oleh laki-laki untuk memotong cabang dan ranting tanaman teh yang menutupi lorong petik mesin. Kekompakan dan kebersamaan yang timbul dan tumbuh antar sesama anggota kelompok mesin petik dalam bekerjasama untuk mencapai tujuan bersama yaitu produktivitas dan pendapatan kelompok yang tinggi, membuat anggota perempuan dapat bekerja lebih nyaman. Simbol kekompakan kelompok petik mesin ditunjukkan perempuan melalui baju seragam kerja yang dimiliki oleh operator perempuan (Gambar 3.).

"Untuk di Gambung Selatan, terdiri atas dua tim mesin petik. .... Kedua tim tersebut akan saling membantu satu sama lain dan mengisi kekosongan apabila dari salah satu tim ada yang berhalangan masuk/sakit". (Wawancara dengan Ibu Eni, tanggal 22 Juli 2018).

"Satu-satunya jenis pekerjaan yang hanya dikerjakan oleh laki-laki adalah ngababad yaitu meratakan pinggiran bidang petik". (Wawancara dengan Ibu Yanti, tanggal 4 Juli 2018 ).

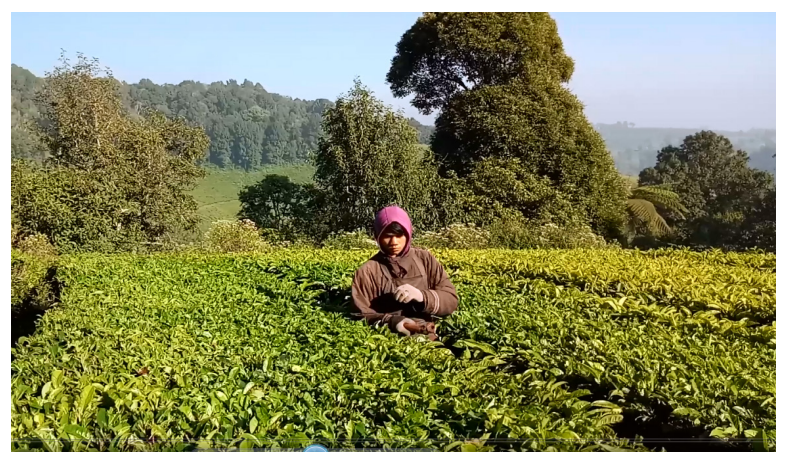

Gambar 2. Pekerja petik mesin laki-laki sedang melakukan pekerjaan babad lorong petik

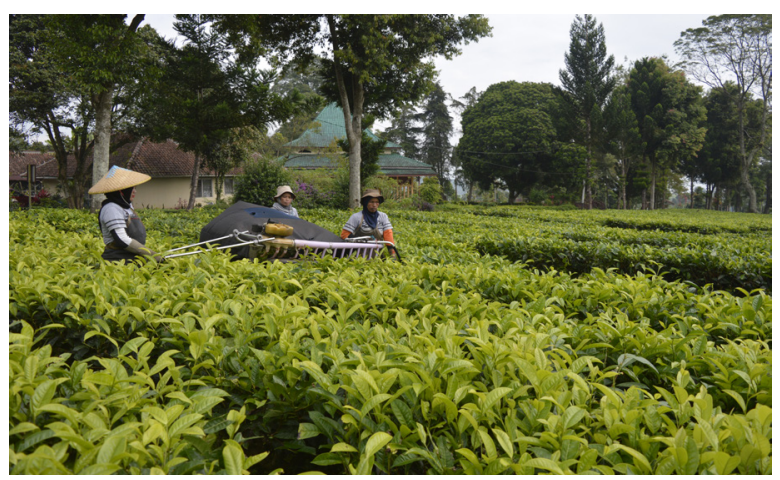

Gambar 3. Kekompakan anggota kelompok mesin petik dalam bekerja dan simbol seragam kerja operator perempuan

Pada awal keterlibatan perempuan dalam kelompok mesin petik, perempuan yang berani mencoba hanya 4 (empat) orang. Mesin petik dengan jenis GT 120 yang telah dioperasikan berasal dari tiga merk, yaitu buatan Jepang dengan merk Kawasaki dan Ochiai, serta buatan China dengan merk Sanyang. Menurut pengetahuan dan pengalaman para operator perempuan, ketiga merek mesin petik terse- 
but masing-masing memiliki kelemahan dan kelebihan. Misal mesin petik buatan Jepang, dirasa lebih berat tetapi kualitas komponen alatnya lebih awet digunakan, tidak mudah rusak, sedangkan mesin petik buatan China dirasa lebih ringan tetapi mudah rusak, walaupun sparepart-nya lebih mudah didapatkan. Hal ini dikemukakan oleh salah seorang operator:

"Mesin petik yang bagus merknya Kawasaki karena mesin awet dan tahan lama, yang sering digunakan sekarang, merek Ochiai dan Sanyang. Mesin Ochiai lebih berat daripada Sanyang, tapi kerusakan lebih sering terjadi pada mesin Sanyang yaitu panbelt sering putus dan balon penampung pucuk sering bolong". (Wawancara dengan Ibu Ari, tanggal 22 Juli 2018).

Penerapan mekanisasi pertanian juga bertujuan untuk meningkatkan produktivitas dan menghemat waktu kerja (Sims dan Kienzle, 2017). Dilihat dari kualitas kerjanya, operator perempuan memberikan hasil kerja yang lebih baik daripada laki-laki. Hal ini karena kemampuan perempuan dalam menjaga kestabilan kerja dalam mengoperasikan mesin petik sehingga kualitas pucuk yang dipetik terjaga. Pemahaman tentang kualitas pekerjaan yang dihasilkan oleh operator perempuan lebih membuka akses pekerjaan dan mempertahankan eksistensi perempuan pada proses panen teh yang sejak dulu memang menjadi serapan tenaga kerja perempuan terbesar di perkebunan teh. Studi FAO (Food and Agriculture Organization, 2011) menunjukkan jika akses perempuan ke sumber daya produktif setara dengan laki-laki, hasil pertanian akan naik 20-30 persen. Kondisi ini akan membuka peluang pemberdayaan perempuan yang lebih besar dalam proses mekanisasi pemetikan teh yang di masa depan proses peralihan petik manual dan gunting ke petik mesin pada perkebunan-perkebunan teh skala luas yang tidak bisa dihindari lagi.
Pemberdayaan perempuan pemetik teh bisa dilakukan dengan meningkatkan kapasitas mereka melalui kegiatan pelatihan keterampilan memetik dengan mesin yang baik dan aman. Seperti yang diungkapkan Verick (2018) bahwa penting untuk memahami apakah perempuan bekerja atau secara aktif mencari pekerjaan, tetapi juga memahami sifat pekerjaan yang dapat diakses oleh perempuan. Maka, memperluas akses pendidikan yang disesuaikan dengan penciptaan pekerjaan yang dapat diakses oleh perempuan adalah sesuatu yang relevan. Hal ini dikemukakan oleh seorang mandor:

"Operator perempuan ternyata lebih stabil kerjanya dari laki-laki yang hanya kuat di waktu awal kerja. Jika operatornya laki-laki semua, lama-lama bidang petik bisa bergelombang karena kelelahan, beda dengan operatornya perempuan atau campuran, tidak mudah lelah dan stabil kerjanya”. (Wawancara dengan Mandor Wanto, tanggal 25 Juli 2018)

Manfaat finansial dari penghasilan yang didapatkan sebagai operator mesin petik cukup tinggi apabila dibandingkan bekerja sebagai pemetik gunting, terutama pada saat masa-masa flush (masa panen pucuk atau pucuk berlimpah). Penghasilan yang didapatkan bisa mencapai Rp. 3.000.000,per bulan, sedangkan pada musim kemarau bisa dibawah Rp.1.000.000,- per bulan. Nilai penghasilan yang diterima perempuan tidak berbeda dengan yang diterima oleh laki-laki, karena sistem pengupahan dalam kelompok petik mesin adalah dibagi rata berdasarkan hasil kinerja kelompok. Namun, walaupun penghasilan ini cukup besar tetapi alokasi pengeluaran untuk kesehatan juga menjadi pertimbangan utama bagi mereka. Hal ini dikemukakan oleh salah seorang operator:

"Bekerja sebagai operator mesin petik, 
penghasilannya memang gede dari gunting, tapi sia-sia juga bila habis tuk beli obat. ..tapi karena kelompok ini sudah seperti keluarga jadi bisa saling bantu bila sewaktu-waktu ada kebutuhan mendesak" (Wawancara dengan Ibu Ari, tanggal 4 Juli 2018)

Di satu sisi, mekanisasi panen teh dengan mesin petik memberikan peluang baru partisipasi dan manfaat yang luas bagi perempuan. Di sisi lain, secara bersamaan juga menawarkan tantangan pekerjaan yang luar biasa bagi perempuan karena memerlukan konsentrasi, latihan dan keterampilan, serta resiko yang tinggi.

Potret kecil partisipasi perempuan dalam petik mesin ini menunjukkan hal yang berbeda dari fenomena sebagian besar partisipasi angkatan kerja perempuan di negara-negara berkembang di mana ketika perempuan bekerja, mereka cenderung berpenghasilan lebih rendah dari laki-laki, bekerja di pekerjaan yang kurang produktif dan cenderung dicerminkan dalam bentuk pekerjaan rumahan yang tidak dibayar (World Bank, 2012). Fenomena teknologi mekanisasi berupa alsintan yang lebih populer dikalangan tenaga kerja laki-laki dibandingkan perempuan juga diungkapkan Suhaeti, Suharni, dan Pangan (2017) di mana faktor hambatan sosial dan institusional yang menjadi penyebabnya, seperti yang terjadi ketika introduksi alat panen padi ani-ani yang digantikan dengan sabit bergerigi pada pertanian padi yang telah menggeser partisipasi tenaga kerja perempuan. Akibat dari mekanisasi pertanian yang belum sensitif gender telah menyebabkan dislokasi skala besar dan pengangguran di kalangan perempuan di pedesaan (Singh, Meena, Kumar, dan Singh, 2013). Setidaknya, potret kecil dari partisipasi sekelompok buruh perempuan di Kebun Gambung dalam pemetikan menggunakan teknologi alat mesin petik dapat menunjukkan bahwa belum tentu mekanisasi dalam panen teh melemahkan atau tidak memberdayakan perempuan. walaupun dalam desain teknologi alat panen teh tetap perlu dikembangkan dan semakin ramah bagi perempuan.

Introduksi teknologi mekanisasi sedikit banyak telah menciptakan pola partisipasi tenaga kerja baru di perkebunan teh, khususnya yang terjadi pada mekanisasi pemetikan teh yang sebelumnya dominan dilakukan perempuan. Namun demikian, perempuan dalam upaya mempertahankan eksistensi dan aktualisasi dirinya, perlahan tetapi pasti, perempuan berusaha keras mencoba untuk sama-sama memperoleh manfaat dari proses dan dampak mekanisasi tersebut. Mekanisasi memang memberikan banyak tujuan, seperti untuk memudahkan dan mengurangi kerja berlebih, mengurangi kekurangan tenaga kerja, meningkatkan produktivitas dan ketepatan waktu operasi pertanian, meningkatkan efisiensi penggunaan sumber daya, meningkatkan akses pasar dan berkontribusi untuk mengurangi bahaya terkait iklim (Food and Agriculture Organization, 2013).

Dengan melihat salah satu potret pengalaman partisipasi perempuan dan hambatan yang dialaminya dalam operasional petik mesin teh di Perkebunan Gambung, maka konsep mekanisasi perlu disandingkan dengan konsep bagaimana menciptakan partisipasi gender baik perempuan dan laki-laki dalam kerangka pembangunan mekanisasi yang berkelanjutan. Kepekaan dan kemampuan adaptasi perempuan terhadap perubahan tidak dapat dipandang sebelah mata, seperti yang diungkapkan oleh GenderCC (2008) dalam Resurrección (2013) bahwa perempuan sebagai powerful agents of changes dan memimpin partisipasi dalam keputusan kebijakan mitigasi dan adaptasi terkait dampak perubahan iklim. Begitu halnya dengan kepekaan perempuan terhadap literasi digital di era industri 4.0, yang ditunjukkan dalam penelitiannya Widyastuti, 
Nuswantoro, dan Sidhi (2016) bahwa untuk menjalankan usaha ekonomi produktifnya, perempuan aktif mengakses internet melalui ponsel pribadinya yang selanjutnya dengan kemampuannya dalam mengakses internet telah dapat meningkatkan keberlanjutan usaha ekonominya. Partisipasi melek digital melalui ponsel pribadi juga telah menjadi rutinitas perempuan operator petik mesin yang bertujuan sebagai sumber media informasi dan komunikasi secara horizontal dan vertikal dalam pekerjaannya, seperti kepada rekan kerja dan mandor (atasan). Pemanfaatan teknologi informasi ini dirasa kelompok sangat efektif sebagai akses informasi dan penyelesaian masalah terkait pekerjaan di kebun sehingga dapat menunjang efektivas dan produktivitas kerja perempuan (lihat Gambar 4.). Selain itu, penampilan perempuan sebagai operator mesin petik teh saat ini lebih fleksibel dengan pakaian kerja casual yang nyaman, tidak membatasi ruang gerak dan aman digunakan selama bekerja di lapangan. Penutup kepala juga menyesuaikan dengan kondisi, dapat berupa topi atau caping serta tidak harus membawa keranjang petik. Keranjang petik atau nama lokal yang dikenal sebagai "kolanding" akan dibawa ketika mesin petik tidak dioperasikan terutama ketika musim kemarau, di mana kondisi pucuk berkurang sehingga dialihkan ke pemetikan dengan menggunakan gunting petik (shear plucking). Kondisi ini berbeda dengan penampilan pemetik teh jauh sebelumnya yang menggunakan tangan untuk memetik teh (hand plucking) seperti yang diungkapkan oleh Grijns (1987) yang semua pemetik perempuan masih identik mengenakan pakaian khas lokal, seperti kebaya, rok kain, bertopi lebar atau caping, serta menggendong keranjang. Hal penampilan yang tetap sama dari pemetik teh di kala dahulu hingga sekarang, baik pemetik teh manual (hand pluckers), pemetik gunting (shear pluckers), dan pemetik mesin (machined pluckers) adalah identik selalu pintar bersolek dan tampil dengan dandanan yang menonjol.

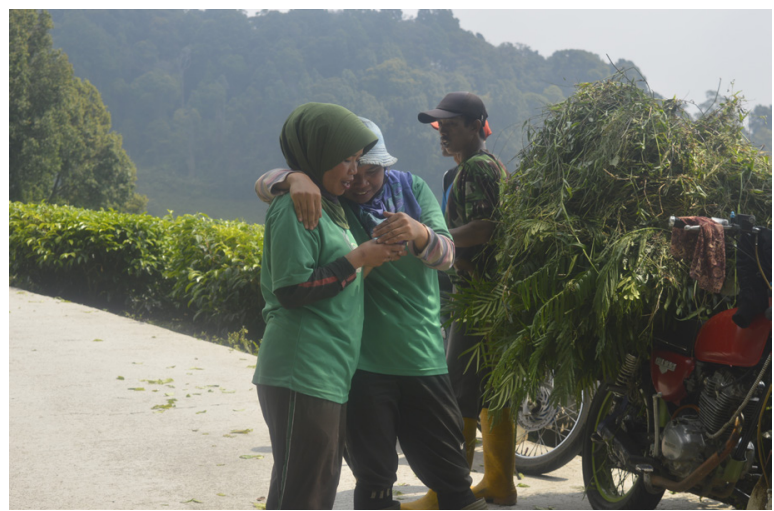

Gambar 4. Operator perempuan sedang melakukan komunikasi kerja via ponsel pribadinya

Houmy, Clarke, Ashburner, dan Kienzle (2013) mengemukakan bahwasannya kini mekanisasi pertanian sedang mengalami kebangkitan dengan penekanan lebih kuat pada solusi yang adil dan berkelanjutan yang membuat mekanisasi pertanian tidak hanya lebih berkelanjutan tetapi juga lebih inklusif. FAO dalam laporannya mengungkapkan tentang mekanisasi berkelanjutan perlu mempertimbangkan aspek teknologi, ekonomi, sosial, lingkungan dan budaya ketika berkontribusi pada pembangunan berkelanjutan sektor pangan dan pertanian (Sims dan Kienzle, 2017). Selain itu, untuk mengurangi gap dalam pembangunan mekanisasi yang berkelanjutan juga sangat dibutuhkan pertimbangan dari aspek gender (Sisei, 2016). Dengan begitu, posisi dan partisipasi perempuan pemetik teh akan terus menjadi bagian penting dalam rantai nilai teh di Indonesia.

\section{Simpulan}

Potret pengalaman partisipasi perempuan pemetik mesin yang tergabung dalam kelompok petik mesin yang beranggotakan 5 (lima) orang per kelompok di Perkebunan Gambung, Jawa Barat telah menunjukkan bukti bahwa proses mekanisasi telah menciptakan pola tenaga kerja (realokasi) gender baru di Perkebunan Gambung. Motif ekonomi dan eksistensi diri men- 
jadi alasan partisipasi perempuan untuk tetap mempertahankan perannya dalam kegiatan panen teh yang selama ini memang menjadi ranah mereka (perempuan). Pengalaman partisipasi aktif perempuan dalam kelompok petik mesin terlihat nyata dalam proses pengambilan keputusan kelompok dan kontribusi mereka baik berupa ide, materi, tenaga, dan keterampilan, kualitas kerja yang dihasilkan lebih baik daripada laki-laki serta pembagian kerja yang cukup adil dan seimbang.

Namun, di tengah usaha keras perempuan untuk turut merasakan manfaat teknologi mekanisasi panen teh tersebut ada banyak kendala yang membatasi adopsi perempuan terhadap teknologi. Kendala tersebut antara lain teknologi yang umumnya masih belum ramah gender, masih kurangnya akses dan kontrol sumber daya, masih terbatasnya kebutuhan akan peningkatan kapasitas keterampilan, hambatan norma budaya, nilai dan asumsi yang telah tertanam di masyarakat di mana perempuan identik dengan pekerjaan yang diasosiakan dengan sifat-sifat halus dan telaten. Dengan demikian, kerangka penerapan mekanisasi pemetikan teh di perkebunan-perkebunan teh di masa depan yang mau tidak mau akan terjadi, perlu mensyaratkan konsep partisipasi gender yang berkelanjutan agar manfaat produktif dapat dirasakan oleh laki-laki dan perempuan. Hal ini juga sebagai bentuk mempertahankan dan meningkatkan posisi dan peran serta perempuan dalam rantai nilai teh di Indonesia secara berkelanjutan. Teknologi akan berhasil meringankan beban kerja perempuan apabila secara fisik mengikuti kebutuhan dan kondisi fisik perempuan, dan inilah teknologi ramah gender.

\section{Daftar Pustaka}

Agus, F. (2016). Environmental and Sustainability Issues of Indonesia Agriculture. Jurnal Penelitian Dan Pengembangan Pertanian. 30(4), 140-147.

Cresswel, J. (2013). Qualitative, quantitative, and mixed methods approaches. In Research Design.

Dalimoenthe, S. L., dan Kartawijaya, W. S. (2000). Mekanisasi dalam pemetikan pucuk teh untuk menanggulangi kekurangan tenaga pemetik. In Pertemuan Teknis Teh Nasional, Bandung (Indonesia), 8-9 November 1999. Puslit Teh dan Kina.

Elianna, Y. P., Dwiningtyas, H., dan Rahmiaji, L. R. (2014). Subjektivitas Seksualitas Perempuan Dalam Novel Pengakuan Eks Parasit Lajang Karya Ayu Utami. Interaksi Online, 8(4), 1-10.

Elias, M. (2015). Enabling gender equality in agricultural and environmental innovation. CGIAR Blog, (December).

Food and Agriculture Organization. (2013). Mechanization for Rural Development : Mechanization for Rural Development : A review of patterns and progress. In Integrated Crop Management Vol. 20-2013.

Grijns, M. (1987). Tea-pickers in West Java as Mothers and Workers: Female Work and Women's Jobs. Indonesian Women in Focus, Eds. Elsbeth Lochner-Scholten and Anke Niehof, 104-119.

Houmy, K., Clarke, L., Ashburner, J., dan Kienzle, J. (2013). Agricultural Mechanization in Sub-Saharan Africa Guidelines for Preparing A Strategy. Integrated Crop Management Vol. 22-2013.

Hubeis, A. V. S. (2010). Pemberdayaan perempuan dari masa ke masa. Bogor: IPB Press.

Huberman, M., dan Miles, M. B. (2002). The qualitative researcher's companion. California: Sage Publications.

Kawarazuka, N., Prain, G., Forsythe, L., Mayanja, S., Mudege, N. N., Babini, C., dan Polar, V. (2018). Gender in Agricultural Mechanization: Key Guiding Questions.

Kusumawati, Y. (2013). Peran Ganda Perempuan Pemetik Teh. Komunitas: International Journal of Indonesian Society and Culture, 4(2), 157-167.

Larasati, T. (2017). Stereotipe Terhadap Perempuan Pengemudi Transportasi Umum Berbasis Online di Jakarta Timur. (Doc- 
toral dissertation, Universitas Airlangga).

Lei, L. (2017). Effects of Standards on Tea Exports from Developing Countries : Comparison of China and Sri Lanka. Institute of Developing Economies (IDE), Discussion Paper, 642.

Lyana, A. C. (2017). Hubungan Antara Komitmen Organisasi Dengan Work Family Conflict Pada Pegawai Negeri Wanita Di Kemdikbud. Jurnal Ilmiah Psikologi, 9(1), 9-16.

Maina, J., dan Kaluli, W. (n.d.). Assessment of Mechanical Harvesting of Tea and Its Viability for Use in Kenya. 207-213.

Nugroho, R. N. (2008). Gender dan Strategi Pengarus-utamaannya di Indonesia. Yogyakarta: Pustaka Pelajar.

Ongong, J., dan Ochieng, A. (2013). Innovation in the Tea Industry: The Case of Kericho Tea, Kenya. Global Journal of Management and Business Research, 13(1).

Puspitawati, H. (2013). Konsep, Teori dan Analisis Gender. Bogor: Departemen Ilmu Keluarga dan Konsumen Fakultas Ekologi Manusia Institut Pertanian.

Resurrección, B. P. (2013). Persistent Women and Environment Linkages in Climate Change and Sustainable Development Agendas. Women's Studies International Forum, 40, 33-43.

Sasongko, S. S. (2009). Konsep dan Teori Gender. Jakarta. Pusat Pelatihan Gender dan Peningkatan Kualitas Perempuan.

Sims, B., Hilmi, M., dan Kienzle, J. (2016). Agricultural Mechanization: A Key Input for Sub-Saharan African Smallholders. In Integrated Crop Management.

Sims, B., dan Kienzle, J. (2017). Sustainable Agricultural Mechanization for Smallholders: What Is It and How Can We Implement It? Agriculture, 7(6).

Singh, K. M., Meena, M., Kumar, A., dan Singh, R. (2013). An Overview of Gender Issues in Agriculture. Available at SSRN 2237993.

Sisei, L. M. (2016). Agricultural Mechanization and Women Entrepreneurs in The Agricultural Sector in Rural Areas. Baraton Interdisciplinary Research Journal, 6,
$150-156$.

Sita, K., dan Herawati, E. (2017). Gender Relation in Tea Plucking Workers: A Case Study of Gender Division of Labour and Gender Relation in Gambung Tea Plantation, West Java. Sodality: Jurnal Sosiologi Pedesaan, 5(1), 1-8.

Suhaeti, R. N., Suharni, S., \& Pangan, B. P. B. T. (2017). Inkorporasi Perspektif Gender dalam Pengembangan Rekayasa Alat dan Mesin Pertanian (Alsintan).

Sukesi, K. (1999). Beberapa Alat Kajian Jender dalam Pembangunan. Makalah Yang Disajikan Dalam Kajian Jender Dalam Pendidikan Dan Peng-Ajaran Malang: Puslit-Lemlit IKIP Malang.

Tangkilisan, H. N. S. (2005). Manajemen publik. Jakarta: Gramedia Widiasarana Indonesia.

Tsusaka, T. W., Orr, A., Msere, H. W., Homann-Kee Tui, S., Maimisa, P., Twanje, G. H., dan Botha, R. (2016). Do Commercialization and Mechanization of A "Women's Crop" Disempower Women Farmers? Evidence from Zambia and Malawi. Agricultural and Applied Economics Association (formerly the American Agricultural Economics Association), 1-26.

United Nations Food and Agriculture Organization, (2011). The State of Food and Agriculture 2010-2011: Women in Agriculture: Closing the Gender Gap for Development. FAO Home, Http://Www. Fao. Org/Docrep/013/I2050e/I2050e00. Htm (Accessed 1 November 2011).

Van Eerdewijk, A., dan Danielsen, K. (2015). Gender Matters in Farm Power. Amsterdam: KIT, CIMMYT and CGIAR.

Verick, S. (2018). Female labor force participation and development. IZA World of Labor.

Widyastuti, D. A. R., Nuswantoro, R., dan Sidhi, T. A. P. (2016). Literasi Digital pada Perempuan Pelaku Usaha Produktif di Daerah Istimewa Yogyakarta. Jurnal Aspikom, 3(1), 1-15.

World Bank. (2008). Gender in Agriculture Sourcebook. In Gender in Agriculture Sourcebook.

World Bank. (2012). Gender Equality in Devel- 
opment. In World Development Report 2012.

World Economic Forum. (2018). The Global Gender Gap Report 2018 | World Economic Forum. In Insight Report. 